\section{Mulheres e loucura: a (des)institucionalizaçáo e as (re)invençốes do feminino na saúde mental}

Women and madness: the (des) institutionalization and the (re)inventions of the feminine in mental health

Thaiga Danielle Momberg Silva ${ }^{1}$ Marcos Roberto Vieira Garcia ${ }^{2}$ Universidade Federal de São Carlos - UFSCar

Resumo

A partir de uma pesquisa qualitativa desenvolvida por meio de observaçáo participante, entrevista aberta e análise de prontuários, o artigo almejou investigar as especificidades das mulheres no processo de desinstitucionalizaçąo na cidade de Sorocaba/SP, considerando como as questóes de gênero
se articulam com a vivenciam sua independênncia diante das marcas da institucuionalizaçăo, levando em consideraçáa todo o silenciamento histórico vivenciado, o que se soma ao estigma da loucura atribuído a elas. Os resultados demonstraram dispositivos de controle da sexualidade e da feminilidade no manicômio e, tela das moradoras. Ressalta-se, a partir disso, a necessidde de interseccionar a discussão da saúde mental com as questôes de gênero, classe e raçà

Palavras--chave: Saúde mental; Serviços Residenciais Terapêuticos; Desinstitucionalizaçăo; Mulheres.

\section{Abstract}

TBased on a qualitative research developed through participant observation, open interview and analysis of patients' records, the article aimed to investigate the specificities of women in the process of deinstitutionalization in the city of Sorocaba / SP, considering how gender issues are articulated
with madness. It also sought to understand how the women who currently reside in the Therapeutic Residences Services (SRTs) experience their with madness. It also sought to understand how the women who currently reside in the Therapeutic Residences Services (SRTs) experience their
independence in the face of the marks of institutionalization, taking into account all the historical silencing experienced, which adds to the stigma of the madness attributed to them. The results demonstrated mechanisms of control of sexuality and femininity in the asylum and, also, outside it, which lead to the infantilization and guardianship of the dwellers. From this, we emphasize the need to intersect the discussion of mental health with issues of gender, class and race.

Keywords: Mental health. Therapeutic Residential Services. Deinstitutionalization. Women.

O presente artigo apresenta uma pesquisa cujo tema é o processo de (des)institucionalização na área da saúde mental em Sorocaba, com o intuito de investigar as especificidades das mulheres egressas de manicômios, considerando como as questóes de gênero se articulam com sua tutela e/ou independência.

Buscou compreender, também, como as mulheres que atualmente residem nos Serviços Residência Terapêuticos (SRTs) vivenciam sua independência diante das marcas da institucionalização, levando em consideração todo o silenciamento histórico vivenciado por estas, o que se soma ao estigma da loucura atribuído

a elas, interseccionando a discussão também pelas categorias de raça e classe.

$\mathrm{O}$ trabalho da pesquisa se consolidou por meio de observaçáo participante de SRTs femininas, análise de prontuários de suas moradoras nos serviços de saúde mental e entrevista aberta com uma delas. A pesquisa ${ }^{3}$ seguiu os parâmetros éticos recomendados, o que incluiu sua explicação minuciosa, a garantia de anonimato para as participantes e a apresentaçáo do Termo de Consentimento Livre e Esclarecido (TCLE). O projeto de pesquisa foi submetido e aprovado pelo Comitê de Ética em Pesquisa da Universidade (referência omitida),

${ }^{1}$ Possui Mestrado em Educaçăo pela Universidade Federal de São Carlos. Possui graduaçẫo em Psicologia pela Universidade Paulista. Atualmente é psicóloga na Prefeitura da Estância Turística de Salto.

${ }_{2}^{2}$ Possui graduaçāo em Psicologia pela Universidade de São Paulo (1992), mestrado em Psicologia Social pela Universidade de São Paulo (2000) e doutorado em Psicologia Social pela Universidade de Sáo Paulo (2007). É professor do Departamento de Ciências Humanas e Educaçăo da campus Sorocaba: coordenador do Grupo de Pesquisa "Saúde Mental e Sociedade" (UFSCAR) e integrante do Núcleo de Estudos para a Prevençố da Aids (NEPAIDS/USP) e do Grupo de Pesquisa Educacāo, Comunidade e Movimentos Sociais (GECOMS/UFSCar); coordenador do Centro de Referência em Educaçăa na Atençáo ao Usuário de Drogas da regiáo de Sorocaba (CRR-UFSCar-Sorocaba).

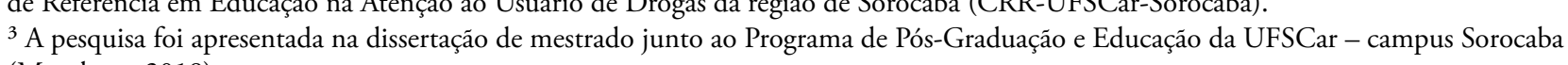
(Momberg, 2018). número do parecer 2.075.850. Também foi submetido e aceito pela área de Divisão de Estágio, Aperfeiçoamento, Especialização e Residência em Saúde da Secretaria de Saúde local.

A relevância do presente estudo está atrelada à mudança da lógica manicomial presente na cidade e a implementação de uma rede substitutiva, entendendo que deve possibilitar novas abordagens, princípios e valores às pessoas em situaçáo de sofrimento psíquico, sendo capaz de impulsionar formas mais adequada de cuidado no seu âmbito familiar, social e cultura (Valverde, 2010)

Segundo Rotelli e colaboradores (2009), a base dos projetos de desinstitucionalização reside na ruptur da causalidade linear da doença-cura, problema-soluçấo, e na reconstruçáo do "objeto" enquanto sujeito histórico. Ainda, ressaltam que as novas instituiçôes devem estar à altura da complexidade da tarefa de intervir na sua existência-sofrimento, remetendo ao processo da constante reconstrução do sujeito. Cabe salientar que as dificuldades de superaçáo do modelo manicomial vão além do mero fechamento de hospitais e da abertura de novos serviços, pois há uma lógica historicamente institucionalizada a ser rompida.

De acordo com o Ministério da Saúde (2004), o Serviço Residencial Terapêutico (SRT) - ou residência terapêutica ou simplesmente "moradia" - "são casas localizadas no espaço urbano, constituídas para responder às necessidades de moradia de pessoas portadoras de transtornos mentais graves, institucionalizadas ou não". (Brasil, 2004, p. 6). A proposta de criaçáo dos SRTs fo desenvolvida com o intuito de possibilitar a redução de leitos dos manicômios, auxiliando as/os moradoras/es na superação da condição cronificante e estigmatizant de "moradores de hospital".

A região na qual Sorocaba se encontra foi até recentemente, o maior da América Latina em termos de concentração de instituiçôes do tipo, passando a ser considerado o maior polo manicomial do país. Sorocaba teve um histórico da presença de manicômios desde a abertura de uma colônia agrícola provisória no fina do século XIX, passando pela abertura de um pequeno manicômio em 1928 e pela grande expansão destes nas décadas de 60 e 70, durante o regime militar, com a contratação de leitos privados pelo sistema público de saúde, o que gerou uma "indústria manicomial" na regiáo (Garcia, 2012). Cabe ressaltar que alguns registros apontam que as condiçóes das/os internas/os nesse manicômio eram de extremo sofrimento e violaçáo de direitos humanos.
Diante desse cenário, o Fórum da Luta Antimanicomial de Sorocaba (FLAMAS) denunciou essas violaçóes que ocorriam no interior dos sete manicômios de Sorocaba e região, o que repercutiu na assinatura de um Termo de Ajustamento de Conduta (TAC), no final de 2012, obrigando os entes federativos (União, Estado e municípios envolvidos) a desativar os manicômios da regiáo em um prazo de 4 anos, o que se configurou como o maior processo de desinstitucionalizaçáo no Brasil recente. O manicômio Vera Cruz tornou-se conhecido nacionalmente como "palco das atrocidades" a partir das graves violaçôes de direitos humanos denunciados no Programa televisivo Conexão Repórter, que registrou pacientes comendo fezes, sem roupas, sem colchão para dormir, além de violência física e verbal por parte dos funcionários e trabalhos forçados, em imagens que chocaram a sociedade, que quase nunca tem acesso ao que ocorre do outro lado dos muros desses espaços.

Buscou-se no decorrer da pesquisa problematizar a saúde mental e a questáo de gênero, defendendo a perspectiva que a saúde mental masculina é tratada de forma distinta da feminina, desde a maneira de se compreender a doença e suas causas, como na forma de tratá-la. De acordo com Scott (1995, p. 11), entende-se gênero, aqui, como "um elemento constitutivo de relaçóes sociais baseado nas diferenças percebidas entre os sexos", e "(...) uma forma primeira de significar as relaçốes de poder".

Para Beauvoir (1980), a mulher foi sempre tratada como o outro, como o segundo sexo, e essas diferenças são produzidas e mantidas no âmbito social e cultural. Ao abordar a questáo de gênero enquanto saber e considerar as relaçóes de poder presentes na diferença entre o que é ser homem e o que é ser mulher, pode-se afirmar que o silêncio e a invisibilidade caracterizam a história das mulheres. O lugar das mulheres no espaço público sempre foi problemático, pelo menos no mundo ocidental. O homem público, sujeito eminente da cidade, encarnava a honra e a virtude. A mulher pública constitui a vergonha, a parte escondida, território de passagem, sem individualidade própria (Perrot, 2007). Para Perrot (2007), a invisibilidade e o silenciamento fazem parte da história das mulheres, pois elas atuam em família, confinadas em casa, sem liberdade, e esta "invisibilidade" é a garantia de uma cidade tranquila, sendo sua aparição, inclusive, motivo de medo.

Cabe ressaltar, ainda, a necessidade de racializar o debate político, levando em consideraçáo que o Brasil foi marcado por mais de 354 anos de escravidáo negra e tornou-se o último país do mundo a aboli-la, 
relembrando a desumanização das pessoas escravizadas, suas dores e tortura e múltiplas violências. De acordo com Davis (2016), a categoria "mulher" pode ser considerada uma armadilha se despojada do seu contexto racial e de classe. Considera que os mitos fundadores $\mathrm{da}$ feminilidade - que são caracterizados pela delicadeza, fragilidade, instinto materno natural, dedicaçáo aos cuidados e submissão - são, na verdade, construçôes sociais e políticas, frutos do capitalismo, que necessit da produção e reprodução no lar de seres humanos para o trabalho, mediante a criação da figura típica da "dona de casa", ao mesmo tempo em que cristaliza o trabalho doméstico como aquele não-produtivo e sem remuneração. A estudiosa também ressalta que as mulheres negras, durante e após a escravidão, trabalharam for-

Segundo Brah (2006), não podemos analisar isoladamente os problemas que afetam as mulheres, muito menos universalizá-los: "Dentro dessas estrutura de relaçôes sociais não existimos simplesmente como mulheres, mas como categorias diferenciadas" (Brah, 2006, p. 341), isto é, os discursos de feminilidades assumem significados específicos a partir das diferenças trajetórias que atravessam não apenas as questôes de gênero, mas de raça, classe, sexualidade, geração, entre outros.

Lugar de ambiguidades e espaço por excelência da loucura, o corpo e a sexualidade femininos inspiraram grande temor aos médicos e aos alienistas, constituindo-se em alvo prioritário das intervençôes normatizadoras da medicina e da psiquiatria. Muitas crenças pertencentes a antigas tradiçôes e no âmbito dos mais variados saberes - muitas das quais remontam à antiguidade clássica - seriam retomadas e redefinidas pelo alienismo do século XIX. Entre os alienados considerados "rebeldes a qualquer tratamento, por razóes mais morais do que propriamente médicas", Pinel incluía as mulheres que se tornavam irrecuperáveis por "um exercício náo conforme da sexualidade, devassidáo, onanismo ou homossexualidade" O temperamento nervoso, intimamente relacionado à predisposiçáo às nevroses e nevraloias, era frequentemente considerado como típico das mulheres, "cujas funçōes especiais ao sexo, em muito contribuem para o seu desenvolvimento". (Eengel, 2006, p. 333).

Marcinik e Mattos (2016) nos convocam a pensar a partir do conceito da interseccionalidade, ou seja, a desconstrução de uma perspectiva universalizante da(s) mulher(es) e das características que são produzidas por concepçôes dominantes. Deve-se ampliar e compreender a racializaçáo do gênero por meio da interseccionalidade das diferenças e compreender o impacto das diversas violências e exclusóes sociais que as questóes étnico-raciais produzem. No contexto da saúde mental, deve-se ampliar o debate das questôes de gênero, raça e classe, que são pouco problematizadas e reproduzem formas de opressões, que reforçam a invisibilidade que essas mulheres vivenciam pelo estigma que carregam enquanto "loucas".

As mulheres da presente pesquisa são negras e pobres. Entende-se que tais componentes facilitam a marginalização e a institucionalização precoce, resultando na manicomialização. A mulher pobre e negra carrega o sofrimento e a estigmatizaçáo desde o passado colonial até os dias atuais. As inúmeras discriminaçóes de gênero, raça e classe se refletem diretamente nas representaçôes em relaçấo ao "ser mulher negra", seja em relação as s trabalho doméstico como seu destino natural, o que favorece a institucionalizaçáo precoce desde a infância, o que inclui a manicomializaçáo. Para Santos (2009), ser mulher e negra no Brasil significa estar inserida em um ciclo de marginalização e de discriminação social.

De acordo com Engel (2006), a loucura das mulheres se refere o tempo todo a uma suposta "essência" feminina e sua sexualidade, enquanto a loucura masculina se manifestaria na capacidade que os homens teriam ou náo em desempenhar seus papeis na sociedade. Assim, a mulher é historicamente diminuída, aprisionada à uma ideia esperada de corpo e sexualidade, enquanto ao homem é atribuída a razão.

Para Garcia (1994), desde o início do século XIX, as mulheres caíram sob o controle psiquiátrico, levando ao confinamento em manicômios. A partir da metade do século XIX, cresceu o número de mulheres internadas em manicômios em relação aos homens, o que está associado ao modo como a doença mental feminina foi encarada como associada à condiçáo das mulheres, a partir da expectativa de que as mulheres estariam sempre na iminência de um ataque "dos nervos".

Pode-se afirmar, também, que o manicômio reproduz os estereótipos de gênero, afinal, enquanto se relegava aos homens as atividades ao ar livre, o que contribuiria para a cura, no caso das mulheres isso se daria por meio do trabalho doméstico, corroborando a ideia que a condição feminina se relacionava aos espaços fechados (Cunha, 1986).

Chesler (1972) considera que os manicômios servem como depósito para as mulheres, que recebem tratamento psiquiátrico desde muito cedo, funcionando como uma família burocratizada, na qual a degradação e a fragmentação do ser passam a ser experienciadas pela paciente mulher e infantilizada. Pode-se afirmar que a proteção de pais e máes é supostamente transferida para as/os profissionais dessas instituiçóes.

\section{MÉTODO}

A pesquisa se concentrou em dois Serviços Residenciais Terapêutico (SRTs) femininos, compostos - cada um - por 10 egressas de um manicômio feminino na cidade de Sorocaba-SP. Caracteriza-se como uma pesquisa de abordagem qualitativa a partir da produçáo de narrativas e tendo como fonte de dados os prontuários, observaçáo participante (apoiada em diário de campo) e entrevista aberta com uma moradora de SRT Também foi utilizado material escrito (cartas) de uma moradora, de acordo com seu pedido, que optou por não gravar entrevista, mas desejou contribuir para a investigação.

A análise de prontuários corresponde a uma modalidade de análise documental. Para Souza, Kantorski e Luiz (2011), que investigam a análise de prontuários no campo da saúde mental, é importante que as informaçóes sejam trabalhadas para torná-las mais compreensíveis, correlacionando-as aos dados oriundos de outras fontes, como é o caso dos diários de campo da observaçáo participante e da entrevista no caso da presente pesquisa.

Os diários de campo, prontuários e entrevista foram analisados a partir da proposta de análise categorial de conteúdo proposta por Bardin (1979). Esta técnica caracteriza-se pela classificação dos elementos a serem analisados por uma diferenciação temática e um reagrupamento subsequente pela analogia estabelecida entre eles. A categorização permite, desta forma, condensar os dados brutos em representações mais simples, o que permite estabelecer inferências e interpretar os dados. Está ligada à ideia, portanto, de busca de uma maior visibilidade dos dados, facilitando o trabalho de relacioná-los o referencial teórico.

Cabe ressaltar que, durante o trabalho de campo, algumas moradoras tiveram dificuldade em se comunicar verbalmente, uma das consequências da institucionalização. Por esse motivo, apenas quatro mulheres serão apresentadas na sequência, ressaltando a utilização de nome fictício visando garantir seu anonimato.

Antônia afirmou ter 43 anos, ser pobre e des financeiras.

"Eu tive depressão né? Não consegui cuidar da minha filha, eu tinha 13 anos, eu descobri tarde e não adiantou tomar o chá, náo desceu, eu me sentia triste, eu era danada, nós era pobre, faltava as coisas, tive irmãos e minha tia náo quis cuidar de mim, fui morar minha tia náo quis cuidar de
com minha vó". (Antônia)

Segundo informaçóes encontradas no seu prontuário:

Na infância Antônia morava com seus pais e sua irmã mais nova, com diversas dificuldades principalmente financeiras. Seu pai veio a falecer quando ela estava com 3 anos de idade. A mãe apresentava problemas de alcoolismo, necessitando sempre de auxílio de membro da família para cuidar das filhas. Por volta dos 6 anos de idade foi morar com Por volta dos 6 anos de idade foi morar com
os avós paternos. Neste local começou a freos avós paternos. Neste local começou a fre-
quentar a escola, onde apresentava dificulquentar a escola, onde apresentava dificul-
dades de aprendizagem e possuía poucos amigos. Após aproximadamente 3 anos, voltou a morar com a máe em uma casa simples com condiçôes precárias e com dificuldades financeiras. Na adolescência apresentava auto-estima rebaixada, insegurança para trabalhar e para relacionamentos amorosos. Trabalhou em diversas casas de família como empregada doméstica (Prontuário médico da paciente Antônia, s. d.).

Antônia é diagnosticada pelo CID 10: F31.0 (Transtorno Afetivo Bipolar) e é descrita em seu prontuário como tendo discurso coerente e pensamento organizado, sendo afetiva e tendo boa interação com todos. É referida como independente e autônoma nas atividades de vida diária, possui seus aspectos cognitivos preservados, assim como atenção, memória e concentraçáo. O prontuário conta, também, que ela apresenta vínculo precário e fragilizado com os irmãos, é curatelada e, desde dezembro de 2014, não tem acesso aos seus benefícios previdenciários.

Já a moradora Maria contou que tem 47 anos e teve uma infância conturbada. Viveu parte de sua infância na rua e foi internada ainda muito jovem na Fundação Estadual para o Bem-Estar do Menor (FEBEM, atual Fundação Casa). Seus sintomas eram caracterizados por agressividade, de acordo com seu prontuário. Após a internaçáo na FEBEM, foi encaminhada ao manicômio, onde residiu mais da metade de sua vida. Também teve uma infância privada de condições financeiras e é negra. Segundo a moradora, "eu fui 
pra FEBEM, vivi lá, náo lembro quando, mas eu era pequena, minha mãe bebia, depois fui pro hospital". Segundo seu prontuário:

Menor internada em 30.11.1982, apresenta boas condiçōes de saúde física, executa satisfatoriamente as tarefas que lhe são atribuidas, porém com certa lentidáo. Apresenta certa timidez, tornando assim muitas vezes um relacionamento difícil tanto com os funcionários como com as demais internas. funcionários como com as demais internas. A menor nunca recebeu visitas, continu-
ará recebendo treinamento nas atividades ará recebendo treinamento nas atividades ais, para que futuramente possamos colocá-la em casa de família como empregada doméstica. (Prontuário da paciente Maria, 16 de maio de 1986)

Consta em seu histórico, de acordo com seu prontuário, que Maria foi internada em 1971, por meio do Juizado de do encontrada em estado de abandono em casa e por sua genitora realizar uso abusivo de álcool, o que acarretou em sua prisáo. $\mathrm{Na}$ sequência, Maria se manteve sob os cuidados da antiga FEBEM, passando por vários abrigos. Em 1986, ela foi transferida para um manicômio em Sorocaba, com diagnóstico de retardo mental leve e episódios esporádicos de agressividade, onde permaneceu por 13 anos. Em 1999, foi transferida para outro manicômio, onde ficou por mais 15 anos. Não há registro de nenhuma visita à paciente e nem procura por ela durante todo $\mathrm{o}$ tempo da internação. Segundo seu prontuário:

Diagnóstico: CID F70.0 (Retardo Mental Leve). É considerada independente nas atividades de vida diária (AVDs) como higiene pessoal e alimentação, boa comunicaçáo, aspectos cognitivos preservados, como orientação temporal e espacial, bem como resoluçóes de problemas, boa convivência com as demais usuárias (Prontuário da paciente Maria, s. d.).

A terceira moradora, Mercedes, não sabe sua idade, aparentando ter 35 anos. Negra e pobre, apresenta dificuldades na linguagem verbal. Não recorda o motivo pelo qual foi internada, mas sabe que o foi ainda na infância. De acordo com seu prontuário, tem 38 anos. Foi encaminhada para a FEBEM com um ano de idade, devido ao abandono familiar. Aos dois anos de idade, foi transferida para um abrigo, onde permaneceu por 12 anos. Em 1991, foi transferida para o por conta do fato do abrigo encerrar suas atividades. Durante todo o processo de internação, não há nenhum registro de visitas e/ou vínculos familiares. Consta em seu prontuário:

Diagnóstico: F70.0 (Retardo Mental Leve). É independente nas Atividades de Vida Diária (AVDs), como higiene pessoal e alimentação. Apresenta certa dificuldade na fala, porém com boa comunicação verbal, aspectos cognitivos preservados, como orientação temporal e espacial, bem como resoluçóes de problem çoes de probs demais usuárias. Apresenta quadro cínico e psiquiátrico estáveis. A paciente é curatelada, porém atualmente seu benefício encontra-se bloqueado pela justiça [...]. (Prontuário da paciente Mercedes, s. d.).

Por fim, Fátima, 25 anos, negra e pobre, passou a viver em um abrigo após a máe perder sua guarda aos 11 anos. Afirma que nunca conseguiu ler nem escrever e foi encaminhada à Associação dos Pais e Amigos dos Excepcionais (APAE) por causa dessa dificuldade. Frequentou essa instituição até ser internada no manicômio. Não se recorda quantos anos tinha quando foi mandada para o hospital, mas se lembra que ainda era criança, tendo ficado, aproximadamente, 15 anos internada.

Eu náo sabia ler, e nem escrever, mandaram eu pra lá, eu queria aprendê, a professora me acusou, dizia que eu era louca, que eu tinha acusou, dizia que eu era louca, que eu tinha
passado fezes na parede, eu não tinha feito nada, fui pro hospital e o juiz falou que eu ia ser moradora. (Fátima).

De acordo com seu prontuário, Fátima tem 25 anos, foi encaminhada para a instituiçáo de acolhimento - "abrigo" - desde os 11 anos de idade, pois os pais reaizavam uso abusivo de bebida alcoólica, além de haver uma suspeita de tentativa de abuso sexual por parte de seu pai. Em 2005, foi transferida para o manicômio devido às crises de agressividade. De acordo com seu prontuário: Recebeu alta, mas foi impedida de retornar ao abrigo devido o mesmo acolher crianças até os 12 anos, Fátima tinha passado desta idade. Assim permaneceu internada, como moradora do Hospital Mental até 23.07.2014. Com o advento do TAC - Termo de Ajustamento de Conduta, esta foi transferida para o Pólo de Desinstitucionalização, onde conheceu seu atual companheiro Tem em seu prontuário a hipótese diagnóstica de "Retardo mental leve".

Fátima carrega desde a infância um histórico de institucionalização. Cabe ressaltar que o motivo que a levou a permanecer enquanto "moradora" do manicômio foi o fato de a instituição de acolhimento não receber mais crianças na sua faixa etária.

\section{RESULTADOS E DISCUSSÃO}

O trecho abaixo, retirado do prontuário de Maria, mulher negra e de classe baixa, desde muito cedo institucionalizada, nos faz refletir sobre a intersecçáo entre gênero e raça:

A menor nunca recebeu visitas, continuará recebendo treinamento nas atividades domésticas, assim como nos trabalhos manuais, para que futuramente possamos colocá-la em casa de família como empregada doméstica. (Prontuário médico da paciente Maria, 16 de maio de 1986).

Segundo Davis (2016), é possível observar uma relaçáo direta entre escravismo e trabalho doméstico. No Brasil ainda se mantém fortemente como uma atividade feita, em sua maioria, por mulheres negras, relembrando também que a escravidáo foi usada como modelo para a precarização do trabalho para a população negra. Devido ao sistema de contratação de pessoas encarceradas, a população negra foi forçada a representar o mesmo papel que a escravidáo anteriormente lhe reservava.

Segundo informaçōes do prontuário, Maria, desde pequena, foi ensinada a desempenhar funçóes domésticas, tida como sua única opção de inserção social fora da instituição. Desde muito cedo, quando fo internada ainda na infância, foi estimulada a aprender o trabalho doméstico, visto como única possibilidade de trabalho formal. Foi, desta forma, privada da educaçáo formal e das inúmeras chances que poderiam surgir, devido à sua institucionalização em espaços para "menores" e manicômios por, praticamente, a vida inteira.

Atualmente, é possível perceber que a rotina de Maria na RT em que reside consiste em realizar tarefas domésticas, auxiliando na limpeza de cozinha, organização de roupas e no cuidado com outras moradoras que possuem pouca ou nenhuma autonomia. Raramente sai da casa. Afirma que náo gosta de passear e que "tem que limpar". As cuidadoras da RT dizem que ela é organizada, "prendada" e que frequentemente ajuda, ficando chateada se náo realiza as atividades. Percebe-se grande organização, limpeza e cuidados nas atividades que realiza. Não é comum encontrar Maria fazendo alguma atividade de lazer, nem sequer sentada no sofá para assistir à televisão, como as demais mulheres. Geralmente, está na cozinha, nos cuidados com roupas de cama, ou auxiliando as cuidadoras e técnica de referência com a medicação.

De acordo com Chesler (1972), as internaçóes em manicômios costumam aproximar mais a mulher do que o homem da experiência familiar, fato que pode ser justificado por elas se sentirem "em casa". A mesma autora ressalta que pacientes mulheres, assim como meninas, são supervisionadas de perto por outras mulheres, enfermeiras atendentes, que são relativamente sem força em termos de hierarquia hospitalar.

Desta forma, pode-se afirmar que a lógica manicomial permanece presente nas RTs em questáo, onde se percebe a "supervisão" das profissionais, bem como o incentivo às mulheres permanecerem nos domínios do privado, realizando atividades diárias, negando-se sua autonomia, a vivência da sexualidade e sua socialização no mundo público, dentre outros aspectos.

Mercedes, também mulher negra e de classe baixa, apresenta características muito parecidas com as de Maria, no que diz respeito à realização das atividades da casa. Frequentemente, auxilia na organizaçáo e limpeza do local e náo faz atividades fora da RT. Segundo a técnica de enfermagem, ela não sai, pois não sabe pegar ônibus e se perde muitas vezes. Ambas costumam sair com a técnica de enfermagem para levar alguma moradora na UBS em consultas, ou em lojas quando precisam comprar algo, prática que era comum quando viviam no manicômio. Outra semelhança em relação a essas mulheres é a "ausência" de uma vida fora da RT, pois quando questionadas sobre suas vidas enquanto mulheres, sexualidade, relacionamentos interpessoais, as duas afirmam que não possuem.

Seu comportamento difere do de Antônia, que tem mais autonomia e costuma realizar passeios com maior independência, além de namorar. É perceptível, no dia a dia, o incômodo de Mercedes e Maria com o comportamento de Antônia, pois a mesma realiza tarefas de limpeza na casa, mas numa frequência menor, e constantemente está realizando outras atividades. Ela gosta de escrever textos e sair com o namorado. Isso gera desconforto também em relação às cuidadoras, que questionam sobre o "apetite sexual" de Antônia, 
quando afirmam que a mesma "apronta demais" quando sai, fazendo refletir sobre a questão de tutela ainda presente nas RTs, onde as mulheres pouco são estimuladas a vivenciar uma vida "comum" como qualquer pessoa adulta, vivenciando sua sexualidade.

De acordo com Chesler (1972), considerando que as mulheres têm tido desde sempre sua sexualidade reprimida, a tentativa de escapar de tal repressão é vista como perigosa pelas/os profissionais do manicômio.

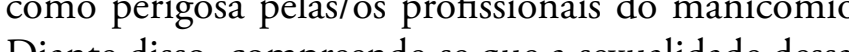
Diante disso, compreende-se que a sexualidade dessas mulheres é entendida como tabu. Seguindo-se a lógica imposta a muitas delas, a manifestaçấo da sexualidade é vista como atrelada à loucura. $\mathrm{O}$ desejo sexual pode existir, desde que seja extremamente controlado, de acordo com um padrão pré-estabelecido de apetite sexual, o que reforça paradigmas sobre o feminino, reprime a sexualidade e demais aspectos que não são encarados como comportamentos adequados a uma mulher.

Antônia afirmou que, desde muito nova, gostava de leitura e escrita, entretanto era pouco incentivada por causa das atividades que ela precisava realizar, provavelmente, em uma referência aos afazeres domésticos, existe um teor de recriminaçáo em relaçáo às meninas negras que se dedicam a atividades individuais, sendo altamente reprovável a abdicação das obrigaçóes domésticas por atividades de leitura e escrita.

Fátima, assim como Maria e Mercedes, não sabe ler e nem escrever, o que reafirma a privação presente já na infância no que diz respeito à escolarização. Cabe ressaltar, ainda, que Fátima era criticada pelas outras moradoras da RT devido ao não-cumprimento de certas "regras". A técnica de enfermagem relatou que ela não "obedecia", queria sair e voltar "do seu modo e quando quisesse", além de náo ajudar nos afazeres da casa. Isso mostra que condutas fora das expectativas de gênero e raça, mesmo mostrando maior autonomia por parte de Fátima, eram objeto de críticas na RT.

Eu acho errado internar a pessoa a força, só interna a pessoa a força se ela quiser. Acho errado. $\mathrm{Na}$ época a gente era chamado de louco, naquela época, eu lembro disso até hoje. Me colocaram na ambulância, tem a gradinha sabe, já ouviu falar da ambulância, me colocavam lá e me chamavam de louca. Desse jeito, aqui agora, nessa residência aqui é um amor, é muito bom. Eu me sinto em casa, mãe D. deixa eu dormir na casa do W. D. é um amor, não tenho o que falar dela. Eu tô bem feliz. (Fátima)
De acordo com o prontuário de Fátima, foi possível observar a transferência de uma RT para a outra, bem como aspectos que demonstram sua autonomia e que incomodavam a gestáo da SRT:

Em junho de 2015 Fátima recebeu alta do Pólo de Desinstitucionalização e foi morar em uma RT, onde continuou com seus comportamentos pueris, com birras e agressividade, se recusando em muitos momentos a comer e tomar suas medicaçóes. Ainda, a comer e tomar suas medicaçós. Ainda,
demonstrava-se frustrada por não receber seu dinheiro do BPC, o qual continua bloqueado devido as questóes judiciais relacionadas com o processo de tutela e curatela. [...] Foi para casa da família em junho de 2016, acompanhada pela referencia técnica da RT, onde morava, para rever a irmã. Deste modo, ficou combinado que iria morar com a mesma dali 30 dias. Entretanto, Fátima depois de alguns dias, relatou que estava bem na RT, considerando estar perto de seu namorado rejeitando a proposta de morar com a irmá. (Prontuário da paciente Fátima, s. d.).

Percebe-se, por meio desse relato, a necessidade de se considerar a capacidade de escolha das pessoas que saem dos manicômios após períodos longos de internaçáo; no caso citado, Fatima passou grande parte de sua infância em instituiçóes asilares, atualmente criando laços afetivos em Sorocaba, embora seus vínculos familiares estejam em outra cidade. Diante disso, teve como preferência a escolha de permanecer em Sorocaba, o que foi respeitado pela equipe técnica. Consta ainda em seu prontuário:

Em julho de 2016 Fátima saiu abruptamente da RT na companhia de seu namorado para morarem sozinhos, sem orientação final da equipe. Desde entấo, residem em uma casa precária onde dividem as despesas com aluguel e alimentaçáo, send guel e alimentaçáo, sendo acompanhada pela equipe do CAPS. Fátima demonstra interesse pelos cuidados da casa, como o preparo das alimentaçóes, enquanto o companheiro preocupa-se com a continuidade do tratamento e administração das medicaçóes. Vale ressaltar que o relacionamento é sempre conflitutar que o relaion oso com muitas discussóes e brigas, quando recorrem aos técnicos da equipe. (Prontuário
da paciente Fátima, s. d.).
Por meio do relato acima, pode-se problematizar a questáo do papel social da mulher interna, que, geralmente, está associada às tarefas concretas do dia a dia, enquanto da figura masculina é esperada maior responsabilidade no sentido racional, embora a questấo da irracionalidade esteja presente em ambos, devido ao estigma de associado ao manicômio. Fátima demonstra autonomia, como aponta seu prontuário:

Em fevereiro de 2017 Fátima foi sozinha de ônibus buscar auxílio da irmã, onde resolveu morar. Entâo sua irmá a acolheu e foi realizado contato com o CRAS para articular a continuidade do tratamento. Em março retornou para sua casa. (Prontuário da paciente Fátima, s. d.).

Fátima, durante entrevista realizada em agosto de 2017, afirmou que decidiu voltar para a RT, pois ela e o namorado brigavam bastante:

"Eu e W. briga demais, não deu certo, mas a gente continua junto, aqui é bom [se referindo à RT atual], posso ver ele, sair, nois briguemos muito. Ele tem os problema dele também né?" (Fátima, agosto de 2017).

De acordo com seu prontuário, após decisão de Fátima voltar a residir em RT, foi pensando em nova inserção em outra residência, o que se deu em abril de 2017, onde Fátima está até os dias de hoje, sem quaisquer dificuldades de adaptaçáo. No seu prontuário, consta que

Fátima questionou sobre seu direito já conquistado [de ir e vir] e me pediu para visitar W. [seu namorado] e ir ao cinema no sábado W. [seu namorado] e ir ao cinema no sabado
com seu namorado. Foi orientada que sim, desde que não atrapalhe seu PTS (Prontuário da paciente Fátima, s. d.).

Entende-se que o campo psiquiátrico desempenha uma funçáo de normalização, padronizando comportamentos considerados aceitáveis para as mulheres egressas de manicômios. Pode-se perceber que a não-adequação a padróes impostos é um fator que contribui para sua internação e institucionalização.

As marcas da institucionalização carregam diferentes formas de opressão, seja por classe, raça, e/ou gênero. Para as mulheres, os limites eram muito mais rígidos, e elas tinham que se encaixar no que era ser mulher, mãe e esposa.
Nem todas as mulheres que viveram na primeira metade do século XX escolheram viver a vida nas formas prescritas. Na população feminina do Sanatório Pinel, podemos encontrar inúmeras histórias de 50 mulheres que buscaram certa autonomia frente às pressóes que a sociedade lhes impunha, mas também mulheres que, mesmo desempenhando uma função a elas delegada, sofreram crises relacionadas a esses papéis. Essas manifestaçōes, aos olhos das "instituiçoes reguladora", foram vistas como sinais de demência e desequilíbrio mental. (Vacaro, 2011, p. 10-11).

A análise dos prontuários das moradoras aqui pesquisadas mostra em muitos momentos a não-correspondência a um comportamento tido como "normal". Entende-se que as mulheres foram historicamente restritas apenas ao papel de "filhas-esposas-mães", e qualquer tentativa de "fugir" deste seu único destino passa a ser julgada, tendo como uma das consequências possíveis a ribuição de "loucura" e sua segregação em manicômios.

Para Cunha (1986), as mulheres, em qualquer situação social, incluindo em situação de internamento, serão inferiorizadas quando comparadas aos homens, evidenciando as diferenças no modo de se compreender a "loucura".

Parâmetros diferentes orientam a construção da "loucura" - e, portanto, da "normalidade" - para cada um dos sexos, remetidos a um desenho idealizado dos papéis sexuais e dos diferentes atributos de gênero. Assim cabia ao homem "normal" a tarefa de provedor da família, de trabalhador dedicado e quanto o "exemplo" de uma vida morigerada e livre dos vícios e dos "excessos". À mulher restavam as tarefas estratégicas da reproduçáo e da conservação da família e do lar, de "ser - para - com - os - outros" conforme exigiriam sua própria determinaçáo biológica e as inclinaçôes naturais do seu espírito. (Cunha, 1986, p. 126).

A história de Antônia, mulher, negra e sobrevivente do manicômio, talvez seja a que melhor exemplifique esse processo. Conforme seu prontuário,

Antônia teve alguns relacionamentos amorosos com homens casados, se envolvendo com várias pessoas na mesma época. Por esse motivo, ao engravidar, não sabia quem era o pai da criança. Durante a gravidez Antônia residia com sua avó materna, sentia-se deprimida, chorava bastante, sentia arrependimento de algumas situaçôes 38 que passou. Após o parto de sua filha, os sintomas de Antônia se intensificaram, apresentando alucinaçôes auditivas e visuais e delírios inclusive 
de cunho persecutório. Permaneceu com sua filha, residindo na casa de sua avó materna, até a menina completar 2 meses de vida. Após isso, foi adotada por um casal que Antônia conhecia. Antônia entấo fora internada no manicômio pela primeira vez. Após sua alta, Antônia passou a visitar a filha, porém foi proibida por essa família de ver a filha pois teria tentado agredi-la algumas vezes. (Prontuário da paciente Antônia, s. d.).

Possuía uma vida promíscua, aos olhos da sociedade, por manter relaçôes sexuais com vários parceiros. Afirmou que, muitas vezes, optava por ter essas relaçóe em troca de roupas e presentes com pouco valor financeiro, visto que vivia em condiçâo de miséria. Sentia-se culpada e deprimida por não conseguir seguir os dogmas impostos pela igreja que foi "obrigada" a frequentar pela tia materna, com quem passou a conviver após o abandono da genitora. É possível perceber que sua condição de "ser louca" se relaciona ao julgamento do modo como a mulher vivencia a sua sexualidade.

De acordo com Hooks (1995), para justificar a exploração masculina branca e o estupro das negras durante a escravidáo, a cultura branca teve de produzir uma iconografia de corpos de negras que insistia em representá-las como altamente dotadas de sexo a perfeita encarnaçáo de um erotismo primitivo e desenfreado.

Pode-se afirmar que a escravidão foi um dos episódios mais violentos da história do povo brasileiro, que a violência esteve presente de todas as formas possíveis e que a mulher negra foi objetificada, reforçando a ideia do corpo enquanto objeto de servidáo para os homens brancos. Isso nos deixou marcas profundas no sentido de naturalizar a violência contra as mulheres, assim como reificar a associação entre mulheres e o trabalho doméstico, e institucionalizar muitas das mulheres consideradas "loucas", em sua maioria negras e de classe baixa, no manicômio, destituindo-as de sua liberdade e de tudo que as caracterizava como humanas.

Segundo Engel (2006), na construçáo dos diagnósticos da doença mental em mulheres, a psiquiatria deu grande destaque à menstruaçáo e à maternidade, considerando que o início e o fim do período menstrual seriam, frequentemente, momentos propícios à manifestaçấo de distúrbios mentais, bem como a maternidade poderia curar ou intensificar a loucura feminina. $\mathrm{E}$ importante ressaltar, nesse discurso, a expectativa de que uma mulher seja capaz de desempenhar a maternidade de modo natural, pois este é seu papel social, atrelado ao seu corpo, restringindo-se, novamente, a figura da mulher a ele. Antônia compartilhou que realizou abortos por conta de algumas gravidezes indesejadas. Contou que tomava chás que a impediam de dar continuidade às gestaçôes. Entretanto, na última vez que engravidou, ela disse que náo conseguiu abortar, pois descobriu tardiamente que estava grávida e não sabia quem era o pai, devido a ter vários parceiros sexuais.

Eu já tinha tomado o chá, minha tia não deixava tomar pílula, na última vez não deu certo, acho que o tempo, sei lá, eu tomei, era uma bruxa que dava o chá, eu era danada, gostava de sair, minha filha nasceu, eu chorava muito, pela doença, cheguei no hospital balançando minha filha, assim, sem estar com ela. (Antônia).

Após o parto, Antônia não conseguiu desempenhar as funçôes de maternagem, afirmando não conseguir realizar os cuidados necessários à criança. Passados três meses do nascimento de sua filha, os sintomas depressivos foram se intensificando, teve surtos frequentes de choro e impulsividade, e foi internada no manicômio, após entregar a bebê para adoção. É possível observar que Antônia não conseguiu desempenhar o papel de boa filha, boa esposa e boa mãe que the era naturalmente esperado pelo fato de ser mulher. A gestaçáo foi indesejada, e após o nascimento, aparentemente, náo conseguiu lidar com a condiçáo de ser máe. Devido as seus comportamen a "in e, por isso, as relaçóes, os laços sociais e familiares foram rompidos em busca da normatização de comportamentos esperados. Seu destino foi o manicômio. Além do mais, vale problematizar a questáo do aborto presente na vida de muitas mulheres, entendendo que, na estrutura da sociedade capitalista, patriarcal e racista, o corpo das mulheres está a serviço da lógica de produção, ou seja, servir ao trabalho doméstico, à manutenção do lar e da vida humana, sendo necessário o cumprimento dos papeis que lhes são fortemente impostos: o de máe e esposa.

O corpo da mulher é visto como o corpo para a reprodução e maternidade. Especialmente para as mulheres negras, trata-se de um corpo que está ali para satisfazer os desejos sexuais, muitas vezes, sendo violado pelo estupro, violência esta fortemente naturalizada pela sociedade.

Outra questão relevante aqui se refere à esterilização das mulheres pobres, que acompanha uma concepção de higienizaçáo e limpeza social. No caso das mulheres que possuem transtornos mentais, presume-se que não devam gerar filhas/os. Desde a entrada nos manicômios, é comum a aplicaçáo de injeçóes de anticoncepcionais. E quando questionadas sobre essa prática, ainda presente na rotina da RT, as cuidadoras afirmam que é para proteção das mulheres, no sentido de náo engravidarem, pois náo teriam condiçóes de desempenhar a funçấo da maternagem, o que mostra a reprodução da negação histórica da autonomia e escolha no caso de mulheres consideradas "loucas". Antônia transgride em sua sexualidade, ao afirmar:

Eu sempre fui danada, gosto de namorar, no manicômio não podia namorar, lá só tinha mulher tamém, e eu acho errado, pela força divina eu conheci J. no V., ele é um urso, me trata bem. (Antônia, maio de 2017).

Percebe-se, a partir das análises feitas, que a loucura feminina transformou-se a transgressão social ou moral em doença mental, por meio de discursos daqueles que detêm o poder, seja ele político, religioso, médico, jurídico ou até mesmo familiar. Além disso, cabe refletir que é vigente um senso de moralidade, construído historicamente por bases cristãs e que dialoga com a ideologia burguesa, que costuma classificar os indivíduos como "bons" ou "maus", em especial as mulheres, de acordo com suas atitudes, favorecendo a construção de um pensamento maniqueísta que gera a invisibilidade das contradiçôes sociais e individualiza os problemas, no qual a minoria é oprimida.

\section{CONSIDERAÇÓES FINAIS}

Os resultados da pesquisa demonstraram a presença e ramificaçáo dos dispositivos de controle da sexualidade e da feminilidade no manicômio e, também, fora dele, o que foi evidenciado pelos diversos mecanismos que levam à infantilizaçáo e à tutela das moradoras. Ressalta-se, também, que esses processos devem ser entendidos a partir de uma abordagem interseccional, que leve em conta a discussão da saúde mental em suas interfaces com as questóes de gênero, classe e raça.

Pode-se afirmar que a relaçáo entre mulheres e loucura deve ser destacada também como uma questáo social, pois aponta para as relaçôes de gênero, culturais e morais, levando em consideraçáo nosso país, extremamente machista e misógino, que também carrega uma herança escravocrata, na qual o corpo da mulher ainda é visto como mercadoria, visão reforçada pela grande mídia e que incita a desvalorizaçáo da mulher, reduzindo-

- a meramente à sua sexualidade e atribuindo distúrbios de saúde mental - por exemplo, a histeria - em qualquer situação que contrarie os argumentos machistas, sexistas (Pocistas.

Portanto, entende-se que o movimento antimanicomial, que visa garantir a liberdade como forma de tratamento para questóes subjetivas e psíquicas, deveria estar fortemente relacionado ao movimento feminista, já que a lógica manicomial também é usada para reprimir e normatizar as diferenças de gênero. $\mathrm{O}$ movimento da luta antimanicomial busca náo apenas a desativaçáo do manicômio como instância física, mas acabar com o poder manicomial e suas estratégias de controle. Portanto, pensar a luta antimanicomial sem considerar as questôes de gênero, classe e raça pode ser arriscado, no sentido de reproduzir violências e de ser subserviente aos interesses racistas e patriarcais. De acordo com Martins et al. (2017), o lema "Por uma sociedade sem manicômios" se vincula à luta pela transformaçáo da sociedade capitalista, mas deve incluir, também, a luta contra o machismo e o racismo. Deve-se atentar, ademais, ao fato que o racismo pode ser (re)produzido, se for abandonada a discussáo da branquitude enquanto privilégio racial, invisibilizando as interseçôes de gênero e raça. No Brasil, negras/os e as/ os indígenas sofrem racismo, extermínio e invisibilização. Ao se ampliar a discussão para as questóes de saúde mental, considerando o histórico das pessoas que foram estigmatizadas como "loucas", é muito provável que se identifique que grande parte das pessoas internadas era negra e de camadas populares, reflexo significativo de nossa herança escravocrata.

É urgente, enfim, refletir sobre nossas lutas no campo da saúde mental, incluindo a discussão do lugar racializado da mulher. Falar e problematizar o racismo exige a reflexão acerca dos lugares que ocupamos, das nossas práticas, e o reconhecimento do lugar privilegiado que as mulheres brancas ocupam. Ser antimanicomial é almejar romper com todos os paradigmas presentes numa sociedade marcantemente manicomial, mas também racista e misógina. De acordo com Roeder (2016), faz-se necessário construir políticas que articulem gênero e saúde mental, possibilitem a comunicaçáo com as diversas áreas de conhecimento e levem em consideraçáo os princípios da equidade e da integralidade nas açôes.

Finalmente, ressalta-se a importância de se refletir e proporcionar outros diálogos no campo da saúde mental que possam contemplar as questóes de gênero, raça, classe e demais categorias, para que seja possível se pensar sobre a desinstitucionalizaçáo de forma plena, de forma a se acabar com lógicas segregacionistas, desumanas e opressoras. Almeja-se, também, que profissionais da saúde, pesquisadoras/es e militantes estejam cientes do compromisso social, sendo necessária e urgente a busca 
por estratégias e potencialidades para que a luta em busca de uma sociedade mais justa e igualitária continue, na qual a liberdade seja um elemento central no cuidado em relação às pessoas consideradas loucas.

\section{REFERÊNCIAS}

BARDIN, Laurence. Análise de Conteúdo. Lisboa: Ediçôes 70, 1979.

BEAUVOIR, Simone de. O segundo sexo: fatos e mitos. São Paulo: Difusão Européia do Livro, 1980. V. 1.

BRAH, Avtar. Diferença, diversidade, diferenciação. Cad. Pagu, Campinas, n. 26, p. 329- 376, jun. 2006.

BRASIL. Secretaria de Atenção à Saúde. Departamento de Açóes Programáticas Estratégicas. Residências terapêuticas: o que são, para que servem. Brasília: Ministério da Saúde, 2004.

CHESLER, Phyllis. Women and Madness. New York: Doubleday, 1972.

CUNHA, Maria Clementina Pereira O espelho do mundo: Juquery, a história de um asilo. São Paulo: Paz e Terra, 1986.

DAVIS, Angela. Mulheres, raça e classe. São Paulo: Boitempo, 2016

ENGEL, Magali. Psiquiatria e Feminilidade. In: DEL PRIORE, Mary (Org). História das Mulheres no Brasil. São Paulo: Contexto, 2006. p. 322-361.

GARCIA, Carla Cristina. Ovelhas na névoa: um estudo sobre as mulheres e a loucura. Rio de Janeiro: Rosa dos Tempos, 1994.

GARCIA, Marcos Roberto Vieira. A mortalidade nos manicômios da região de Sorocaba e a possibilidade da investigaçáo de violaçóes de direitos humanos no campo da saúde mental por meio do acesso aos bancos de dados públicos. Rev. psicol. polít., São Paulo, v. 12, n. 23, p. 105-120, jan. 2012

HOOKS, Bell. Intelectuais Negras. Revista Estudos Feministas, Florianópolis, v. 3, n. 2, p. 464, jan. 1995.

MARCINIK, Georgia Grube; MATTOS, Amana Rocha. Branquitude e racialização do feminismo: um debate sobre privilégios. In: OLIVEIRA, João Manuel de; AMÂNCIO, Lígia (Orgs.). Géneros e sexualidades: Interseçóes e Tangentes. Lisboa: Centro de Investigação e de Intervenção Social (CIS-IUL), 2017. p. 159-173.

MARTINS, Beatriz Adura et al. (Ainda) Por uma sociedade sem manicômios: experiências do Núcleo Estadual da Luta Antimanicomial do Rio de Janeiro. O Social em Questão, Rio de Janeiro, ano XX, n. 37, p. 221-238, jan./abr. 2017.
MOMBERG, Thaiga. Entre lírios e delírios: a (des) institucionalização e as (re) invençóes do feminino na saúde mental de Sorocaba. 2018. 84 f. Dissertação (Mestrado em Educação) - Centro de Ciências Humanas e Biológicas, Universidade Federal de São Carlos, Sorocaba.

PERROT, Michele. Minha história das mulheres. São Paulo: Contexto, 2007.

ROEDER, Maika Arno. Gênero e Saúde Mental nos Serviços Residenciais Terapêuticos: fragmentos de vidas contidas. São Paulo: Phorte, 2016.

ROTELLI, Franco; AMARANTE, Paulo Duarte de Carvalho. Reformas psiquiátricas na Itália e no Brasil: aspectos históricos e metodológicos. In: BEZERRA JR., Benilton; AMARANTE, Paulo Duarte de Carvalho (Orgs.). Psiquiatria sem hospício: Contribuições

SANTOS, Walkyria Chagas da Silva. A mulher negra brasileira. Revista África e Africanidades, Rio de Janeiro, ano 2, n. 5, p. 1-5, maio 2009.

SCOTT, Joan Wallach. Gênero: uma categoria útil de análise histórica. Educação \& Realidade, Porto Alegre, v. 20, n. 2, p. 71-99, jul./dez. 1995

SOUZA, Jaqueline, KANTORSKI, Luciane Prado, VILLAR, Margarita Antônia. Análise documental e observação participante na pesquisa em saúde mental. Revista Baiana de Enfermagem, v.25, n.2, p. 2218, 2011

VACARO , Juliana Suckow. A Construção do Moderno e da Loucura: Mulheres no. Sanatório Pinel de Pirituba (1929 - 1944). 2011. 63 f. Dissertação (Mestrado em História Social) - Faculdade de Filosofia, Letras e Ciências Humanas, Universidade de São Paulo, São Paulo.

VALVERDE, Dayana Lima Dantas. Reforma Psiquiátrica: Panorama Sócio-histórico, Político e Assistencial. Rede PSI, 21 nov. 2010.

\section{Endereço para correspondência:}

UFSCar - Universidade Federal de São Carlos

Rod. Washington Luiz, s/n,

São Carlos - SP,

CEP: 13565-905,

Thaiga Danielle Momberg Silva

thaigamomberg@hotmail.com

Recebido em 24/08/2018

Aceito em 17/10/2018 